\title{
Advances in mid-infrared spectroscopic imaging for analysis of breast cancer associated microcalcifications
}

Bouzy, Pascaline; Tseng, Yu Pei; Pedersen, Christian; Tidemand-Lichtenberg, Peter; Palombo, Francesca; Stone, Nick

\section{Published in:}

Proceedings of Mid-Infrared Coherent Sources 2018

Link to article, DOI:

10.1364/MICS.2018.MT3C.8

Publication date:

2018

Document Version

Peer reviewed version

Link back to DTU Orbit

Citation (APA):

Bouzy, P., Tseng, Y. P., Pedersen, C., Tidemand-Lichtenberg, P., Palombo, F., \& Stone, N. (2018). Advances in mid-infrared spectroscopic imaging for analysis of breast cancer associated microcalcifications. In Proceedings of Mid-Infrared Coherent Sources 2018 [Paper MT3C.8] Optical Society of America (OSA). Optics InfoBase Conference Papers Vol. Part F87-MICS 2018 https://doi.org/10.1364/MICS.2018.MT3C.8

\section{General rights}

Copyright and moral rights for the publications made accessible in the public portal are retained by the authors and/or other copyright owners and it is a condition of accessing publications that users recognise and abide by the legal requirements associated with these rights.

- Users may download and print one copy of any publication from the public portal for the purpose of private study or research.

- You may not further distribute the material or use it for any profit-making activity or commercial gain

- You may freely distribute the URL identifying the publication in the public portal 


\title{
Advances in Mid-Infrared Spectroscopic Imaging for Analysis of Breast Cancer Associated Microcalcifications
}

\author{
Pascaline Bouzy $^{1}$, Yu-Pei Tseng ${ }^{2}$, Christian Pedersen ${ }^{2}$, Peter Tidemand-Lichtenberg ${ }^{2}$, Francesca Palombo' ${ }^{1}$, \\ Nick Stone ${ }^{1}$ \\ ${ }^{1}$ School of Physics and Astronomy. University of Exeter, Stocker Road, Exeter, EX4 4QL, UK \\ ${ }^{2}$ DTU Fotonik, Technical University of Denmark, DK-4000 Roskilde, Denmark \\ P.Bouzy@exeter.ac.uk
}

\begin{abstract}
Microcalcifications are an important hallmark of breast cancer and their composition correlates with the degree of pathology. This study used mid-infrared spectroscopic imaging to assess the chemical composition of breast microcalcifications to aid disease diagnosis.

OCIS codes: (170.0170) Medical optics and biotechnology; (110.0110) Imaging systems; (180.0180) Microscopy; $(\underline{300.0300)}$ Spectroscopy.
\end{abstract}

\section{Introduction}

Breast cancer is the most common cause of cancer in women worldwide [1]. The mortality from this cancer in developing countries is increasing because of the late diagnosis. In this context, microcalcifications are the unique early marker of breast cancer [2], having a composition that correlates with the degree of pathology.

Many studies suggest that vibrational spectroscopy, which is non-destructive, label-free and chemically specific, has the ability to provide characteristic 'fingerprints' for these microcalcifications based on their composition e.g. content of phosphate, protein and carbonate [2]. Our approach proposes to use Fourier Transform Infrared (FTIR) spectroscopic imaging in combination with novel IR technologies such as Quantum Cascade Laser (QCL) and upconversion cameras to improve detection and compositional analysis of breast cancer associated microcalcifications to aid diagnosis [3]. This IR spectroscopic data will be used to determine the level of carbonate substitution in each breast biopsy microcalcification and correlate this to the degree of the pathology.

There are different advantages of these novel technologies. In fact, upconversion detectors are used at room temperature without using liquid nitrogen cooling and are cheaper than a Mercury Cadmium Telluride (MCT) detector [4]. QCL source are more intense light source and allows selecting individual wavelength of interest faster than Globar thermal source [3].

\section{Results and discussion}

The FTIR spectral features of standard minerals with different percentage of carbonate substitution that could be found in breast cancer have been characterized using Attenuated Total Reflection (ATR) FTIR spectroscopy. There are two specific bands in the long wavelength region that are attributed to phosphate and carbonate ions at around 9.8 and $11.4 \mu \mathrm{m}$, respectively (Fig. 1).

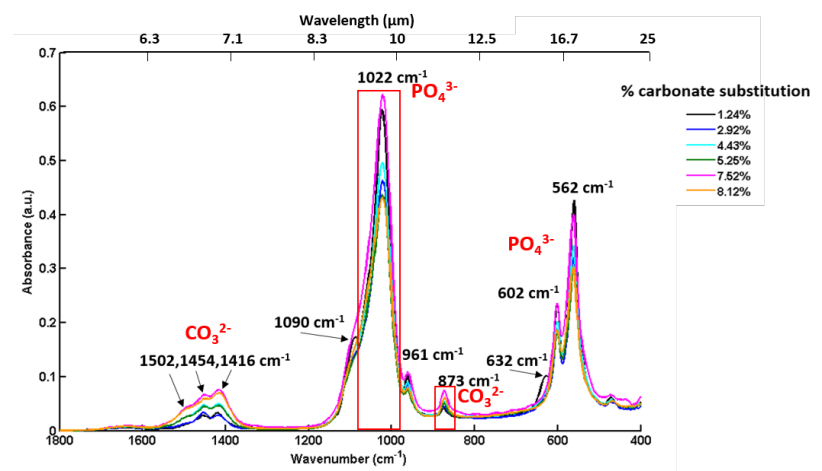

Fig. 1 Representative ATR-FTIR spectra of standard minerals with different percentage of carbonate substitution. 
These bands have been analyzed using spectral decomposition algorithms to relate a phosphate-to-carbonate absorption ratio to a composition ratio to use for calibration.

The next step was to analyze breast cancer biopsies in order to determine the level of carbonate substitution contained in the microcalcifications based on the calibration above. A comparison between spectra obtained from different imaging devices - a commercial micro-FTIR imaging system with a Globar thermal source and an upconversion system coupled to a QCL source - has been performed, as illustrated in Fig. 2.

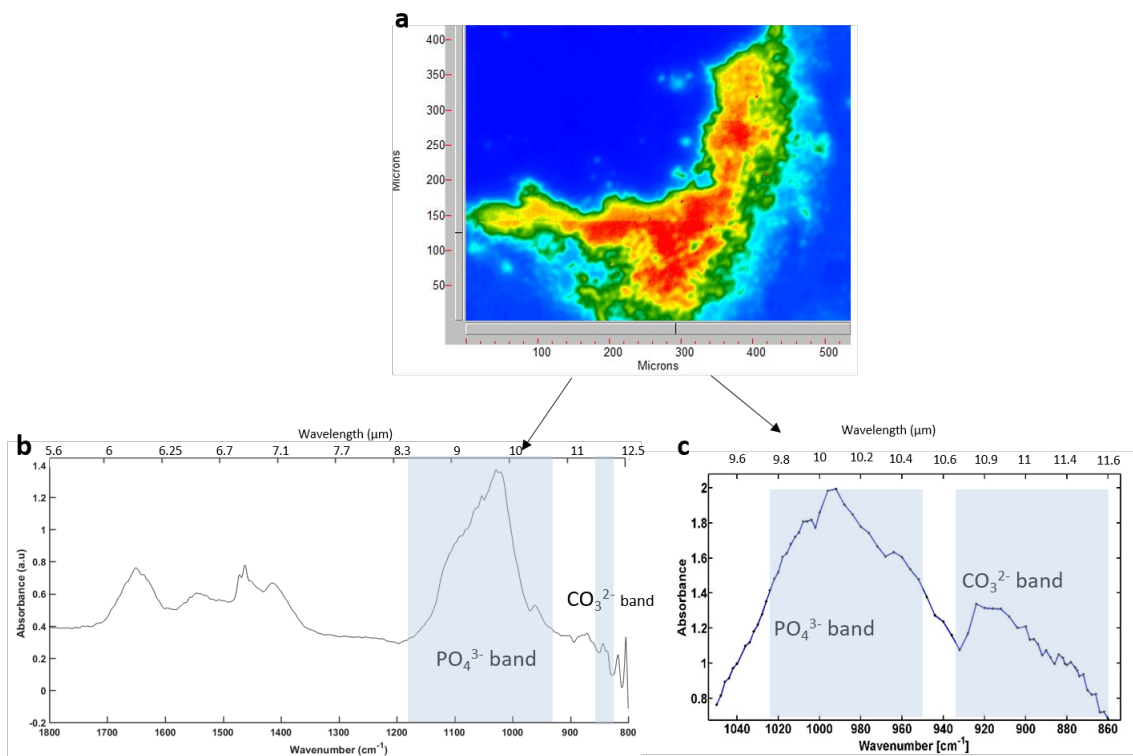

Fig. 2 (a) Micro-transmission FTIR image of a breast cancer biopsy section based on the phosphate peak absorbance, in the range 9.8-10.4 $\mu \mathrm{m}$ (b) Spectrum extracted from the microcalcification shown in (a), and (c) spectrum extracted from the same location as (b) but measured using upconversion and QCL system.

In Fig. 2, an image of a microcalcification is presented (a) along with a representative spectrum (b) obtained using the commercial micro-FTIR imaging system. This has the advantage of accessing a broad spectral range but is limited in that only the phosphate peak can be well characterized. However, the QCL and upconversion system gives access to both phosphate and carbonate bands (c) relevant for the breast calcification analysis. This is promising for the clinical prospect of using a QCL and upconversion system.

\section{Conclusion}

This study has shown a direct comparison between a commercial micro-FTIR spectroscopic imaging system and a QCL and upconversion system in terms of capability to measure breast cancer microcalcifications in ex vivo tissue biopsies. A preliminary analysis has focused on a collection of standard minerals for calibration purposes. As only a few discrete frequencies are required to identify the calcifications and their relative carbonate content (around 11.4 to $9.8 \mu \mathrm{m}$, corresponding to phosphate and carbonate bands) QCL systems could provide a fast scanning of large tissue areas when compared to the current micro-FTIR imaging system, thus promising new avenues for disease diagnosis.

\section{Funding}

Mid-TECH H2020-MSCA-ITN-2014 Grant agreement number: 64266.

\section{References}

[1] www.who.int

[2] R. Baker, KD Rogers, N. shepherd and N. Stone "new relationships between breast microcalcifications and cancer" British Journal of Cancer 103, 1034-1039 (2010).

[3] M.J. Philling, A. Henderson, and P.Gardner "Quantum Cascade Laser Spectral Histopathology: Breast Cancer Diagnostics Using High Throughput Chemical Imaging" Anal. Chem. 89 (14), 7348-7355 (2017).

[4] P. Tidemand-Lichtenberg, J. S. Dam, H. V. Andersen, L. Høgstedt, and C. Pedersen "Mid-infrared upconversion spectroscopy" J. Opt. Soc. Am. B 33(11), D28 -D35 (2016). 